\title{
THE METABOLISM OF ESTROGENS BY THE HUMAN LIVER STUDIED IN VITRO ${ }^{1,2}$
}

\author{
By HENRY J. TAGNON, S. LIEBERMAN," PHYLliS SCHLLMAN, AND \\ ALEXANDER BRLNSCHWIG \\ (From the Sloan-Kettering Institute for Cancer Rescarch and Mcmorial Hospital, \\ New York, N.Y.)
}

(Submitted for publication November 5, 1951 : accepted January 21, 1952)

In the preceding paper (1) a method was described which permits the simple colorimetric estimation of microgram amounts of estrogens in the presence of tissues. The results obtained by the use of this method in a study of the in vitro metabolic action of rat liver on $17-\beta$ estradiol were also reported.

In the present paper we are reporting a similar study on human liver. The original motive for this study was to evaluate whether a deficiency of the metabolic function of the liver exists in patients with cancer of the uterus. Patients with this type of cancer and other diseases were studied.

\section{METHODS}

The procedures described in the preceding paper for the incubation of liver slices, the extraction of the estrogens and the colorimetric method for the measurement of estrogens were used in the present work and found to be applicable without modification to the study of human liver.

Human liver specimens were obtained at laparotomy from patients with various surgical diseases. The patients were unselected. The liver specimen was immersed into ice-cold Krebs solution in the operating room, immediately transferred to the laboratory and the incubation experiment begun. The time interval between surgical removal of the specimen and the beginning of the incubation period did not exceed 10 minutes and was comparable to the time interval obtaining in the experiments with rat liver.

The liver specimen consisted of a wedge of tissue resected from the anterior border and weighing approximately 2 gms. Sufficient tissue was available in each case to run the metabolic, the control and the blank experiments with slices from the same bloc of tissue.

After slices were obtained from the liver biopsy, the

1 Presented in part at the 1951 meeting of the American Society for Clinical Investigation, April 30th, Atlantic City, N. J.

2 This work was supported in part by a grant from the National Cancer Institute of the U. S. Public Health Service.

3 Present address: Columbia University, College of Physicians and Surgeons, New York, N. Y. remaining tissue was fixed in formalin and sectioned for morphologic examination. ${ }^{4}$ Thus the histologic sections in each case came from the area immediately adjacent to that furnishing the slices for the metabolic experiments.

There were three male and nine female patients in this series ranging in age from 31 to 75 . All were white except Case 3 who was a Negro.

The overall clinical and laboratory data pertinent to this study are presented in Table I. The diagnoses were based on surgical exploration and pathologic examination of operative specimens. All patients received preoperative medication in the form of the usual dose of atropin, nembutal and morphine or demerol. All patients received a general anesthesia by ether and oxygen. Liver biopsies were usually obtained shortly after laparotomy. Additional data of significance for certain patients are presented as follows.

Case 1: This patient had a carcinoma of the cervix for which she underwent a radical hysterectomy in December, 1947. Recurrent carcinoma was discovered in December, 1950 and she then underwent the operation during which a liver biopsy was obtained.

Case 2: This patient had an epidermoid cancer of the cervix, leiomyoma, atrophic endometrium and chronic salpingitis. A radical hysterectomy was performed in March, 1951 and she underwent a laparotomy for recurrence of the cancer in July, 1951, at which time the liver biopsy was obtained.

Casc 5: This patient had an epidermoid cancer of the cervix treated eighteen years ago by radium and $\mathrm{X}$-ray. On February 20, 1951, an exploratory laparotomy was performed and multiple peritoneal metastatic implants were discovered. There were no liver metastases.

Case 6: This patient had a papillary adenocarcinoma of the cervix for which she underwent a total hysterectomy and bilateral ovariectomy on June 30,1950 . X-ray therapy was given from September 11, 1950 to October 9, 1950. On March 22, 1951 she had an exploratory laparotomy which failed to demonstrate the presence of cancer. The liver biopsy was obtained during this laparotomy.

Case 8: This patient underwent a left radical mastectomy for breast carcinoma in 1948. On March 30, 1951 she underwent a partial hepatectomy (left lobe and anterior portion of the right lobe immediately anterior to the porta hepatica) for liver metastasis. The metabolic ex-

\footnotetext{
${ }^{4}$ Microscopic examination of the liver specimens was performed by Dr. Arthur Allen of the Department of Pathology.
} 
TABLE I

Metabolism of estradiol by human liver in vitro

$300 \mathrm{mg}$. of liver incubated with 100 micrograms of $17-\beta$ estradiol for three hours at $37^{\circ} \mathrm{C}$.

\begin{tabular}{|c|c|c|c|c|c|c|}
\hline Case No. & Age & Diagnosis & Operation & $\begin{array}{c}\text { Recovery } \\
\text { with boiled } \\
\text { liver }\end{array}$ & $\begin{array}{c}\text { Recovery } \\
\text { with fresh } \\
\text { liver }\end{array}$ & $\underset{\text { metabolized }}{\text { Amount }}$ \\
\hline $\begin{array}{l}1 \mathrm{CC} \\
2 \mathrm{WM} \\
3 \mathrm{FL} \\
4 \mathrm{AM} \\
5 \mathrm{HA} \\
6 \mathrm{TM} \\
7 \mathrm{ST} \\
8 \mathrm{ER}\end{array}$ & $\begin{array}{l}68 \\
53 \\
31 \\
39 \\
75 \\
30 \\
30 \\
44\end{array}$ & $\begin{array}{l}\text { Recurrent carcinoma cervix } \\
\text { Epidermoid carcinoma cervix } \\
\text { Epidermoid carcinoma cervix } \\
\text { Adenocarcinoma corpus uteri } \\
\text { Papillary adenocarcinoma uterus } \\
\text { No disease } \\
\text { Ovarian cyst benign fibromyoma } \\
\text { Metastatic mammary carcinoma }\end{array}$ & $\begin{array}{l}\text { Excision } \\
\text { Excision } \\
\text { Hysterectomy } \\
\text { Hysterectomy } \\
\text { Exploratory laporatomy } \\
\text { Exploratory laporatomy } \\
\text { Removal of cyst } \\
\text { Partial hepatectomy }\end{array}$ & $\begin{array}{c}\text { micrograms } \\
94 \\
94 \\
83 \\
107 \\
65 \\
76 \\
81 \\
87\end{array}$ & $\begin{array}{c}\text { micrograms } \\
51 \\
65 \\
57 \\
62 \\
42 \\
73 \\
59 \\
57\end{array}$ & $\begin{array}{c}\text { micrograms } \\
43 \\
29 \\
26 \\
45 \\
23 \\
3 \\
22 \\
30\end{array}$ \\
\hline $\begin{array}{l}9 \mathrm{AG} \\
10 \mathrm{GC} \\
11 \mathrm{SM} \\
12 \mathrm{VR}\end{array}$ & $\begin{array}{l}41 \\
63 \\
53 \\
50\end{array}$ & $\begin{array}{l}\text { Cancer breast-hemochromatosis } \\
\text { Adenocarcinoma colon } \\
\text { Metastatic carcinoma liver } \\
\text { Metastatic carcinoma liver- } \\
\text { biliary cirrhosis }\end{array}$ & $\begin{array}{l}\text { Bilateral oophorectomy } \\
\text { Colectomy } \\
\text { Partial hepatectomy } \\
\text { Exploratory laporotomy }\end{array}$ & $\begin{array}{l}95 \\
90 \\
90 \\
99\end{array}$ & $\begin{array}{l}54 \\
59 \\
69 \\
62\end{array}$ & $\begin{array}{l}41 \\
31 \\
21 \\
37\end{array}$ \\
\hline
\end{tabular}

Summary of results

I. Boiled liver incubated with 100 micrograms $17-\beta$ estradiol

$\begin{array}{ll}\text { No. of experiments } & 12 \\ \text { Mean recovery } & 88 \\ \text { Mean deviation } & 11\end{array}$

II. Fresh liver incubated with 100 micrograms $17-\beta$ estradiol

$\begin{array}{lc}\text { No. of experiments } & 12 \\ \text { Mean recovery } & 59 \\ \text { Mean deviation } & 8 \\ \text { Mean amount metabolized } & 29 \text { micrograms } \\ \text { Mean deviation } & 11\end{array}$

periment in this case was carried out with liver tissue free of metastatic contamination.

Case 9:5 This patient had a left radical mastectomy two years previously for mammary carcinoma. In May, 1951 she presented evidence of mammary carcinoma of the right breast and of hemochromatosis (diagnosis based on a biopsy of the skin and of the liver). Mild diabetes was present. Serum bilirubin level was $0.6 \mathrm{mg}$. Bromsulfalein retention at 45 minutes was $9 \%$, cephalin flocculation test was 1 plus at 48 hours, thymol turbidity was $6.7 \mathrm{cc}$. of barium sulfate suspension (2) ; alkaline phosphatase was 3.7 glycerophosphate units. On May 14, 1951 she underwent a laparotomy for bilateral oophorectomy, during which the liver biopsy was obtained. A photograph of a section of the liver is shown in Figures 1 and 2 ; it reveals marked alteration in lobular architecture with striking periportal fibrosis and a conspicuous increase in lymphocytes and histiocytes in the periportal areas. In addition there is an abundant hemosiderosis not only of the periportal histiocytes but also of the epithelium of bile ducts and of the parenchymal cells. No Mallory bodies were present. Stains for hemofuscin were not done. A skin biopsy was also examined and diagnosed as hemochromatosis.

Case 11: This patient had an abdomino-perineal resection for carcinoma of the rectum six years previously and

${ }^{5} \mathrm{We}$ are indebted to Dr. Guy Robbins for biopsy specimens and permission to use this case.

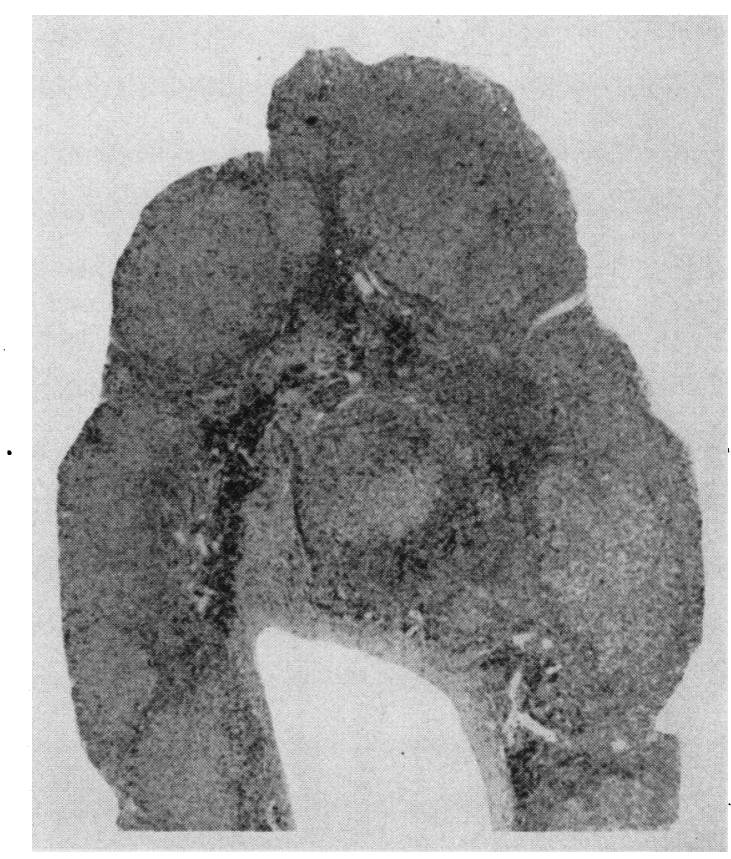

Fig. 1. Photomicrograph of Section of Liver from Case 9 Showing the Hemosiderosis, Fibrosis and LobuLar Irregclarity of HeMochromatosis

Magnification $60 \times$. Hematoxylin eosin. 


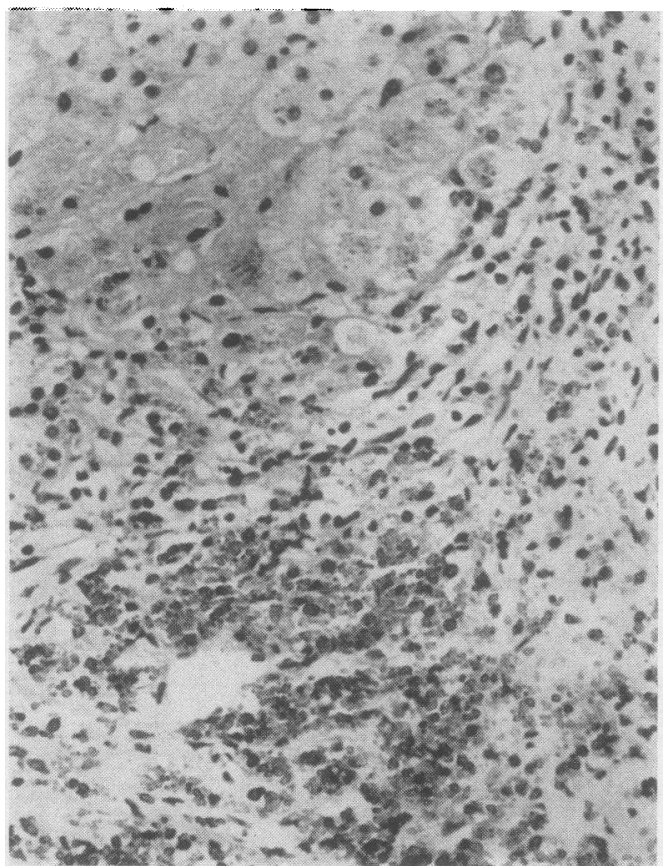

FIG. 2

Same as Figure 1. Magnification $400 \times$.

underwent a left partial hepatectomy for a single metastatic nodule $10 \mathrm{~cm}$. in diameter located in the left lobe of the liver. Liver tissue for the metabolic experiment was obtained from the tumor-free portion of the surgical specimen: morphological examination showed the experimental portion of tissue to be entirely normal. There was no clinical or laboratory evidence of liver dysfunction in this patient.

Case 12: This patient underwent an exploratory laparotomy for jaundice which revealed multiple metastases in both lobes of the liver; the primary tumor was unknown. A biopsy from a region of the liver adjacent to the metastatic tumor was used for the metabolic experiment: morphologic examination of this biopsy showed biliary cirrhosis with acute and subacute cholangiolitis (Figure 3 ). There was also a very small subcapsular focus of metastatic adenocarcinoma seen in this section.

The serum bilirubin level in this patient was $6.6 \mathrm{mg}$. but no other evidence of liver dysfunction was present.

In summary, there were two patients in this series (Nos. 9 and 12) who showed clinical and pathologic evidence of liver diseases. In addition two patients (Nos. 8 and 11) had metastatic liver disease but showed no clinical evidence of liver disease and the biopsy specimens used for metabolic experiments showed an entirely normal structure. The remaining eight patients had normal livers by clinical observation and morphologic examination.
RESULTS

1) Recovery experiments: In the previous paper (1) recovery experiments were carried out with boiled rat liver slices in order to test the accuracy of this method. Similar experiments with boiled human liver slices were carried out here. In 12 experiments using one hundred micrograms of $17-\beta$ estradiol incubated with $300 \mathrm{mg}$. of boiled human liver slices for three hours, the mean recovery was 88 micrograms with a mean deviation or sigma value of 11 micrograms.

2) Metabolism of estradiol 17- $\beta$ by human liver slices: When 100 micrograms of estradiol were incubated at $37^{\circ} \mathrm{C}$. with $300 \mathrm{mg}$. of fresh liver slices for three hours, the decrease in color-producing material expressed as estradiol averaged 29 micrograms in 12 experiments using specimens from 12 different patients; the sigma value was 8 micrograms.

Individual experiments are shown in Table I. In each case a recovery and a metabolic experiment were carried out simultaneously with slices from the same bloc of tissue. The amount of $17-\beta$ estradiol metabolized was calculated by subtracting

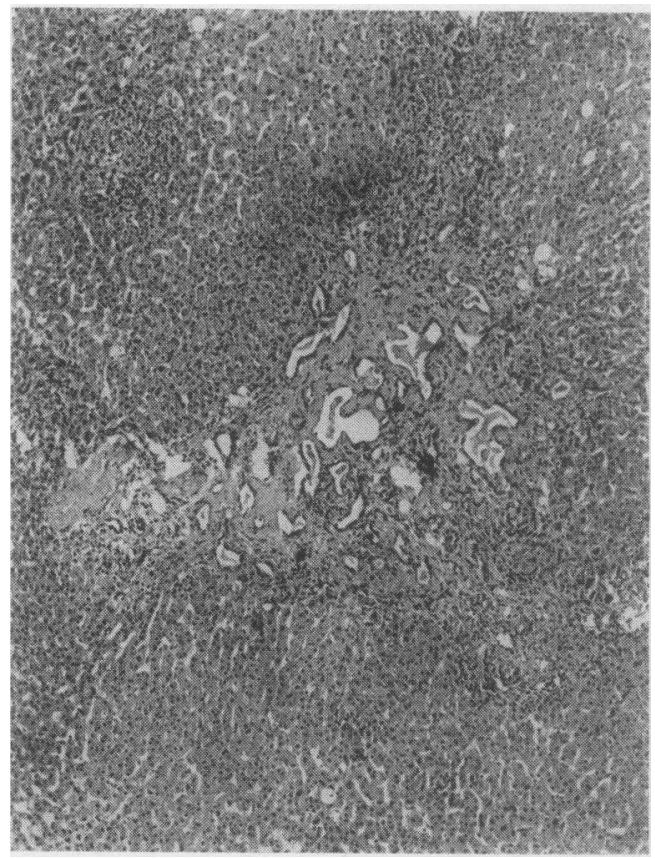

Fig. 3. Photomicrograph of Section of Liver from Case 12 Showing the Proifferation of Bile Ducts and Periportal Fibrosis

Magnification $200 \times$. Hematoxylin eosin. 
the amount recovered after incubation of fresh tissue with estradiol from that obtained after incubation of boiled tissue with estradiol. The results show great individual variations extending from 3 micrograms to 45 micrograms. No correlation could be found in this series between the metabolic activity and the nature of the disease, the age or other data from the clinical history. Of special interest is the fact that the liver from the three patients with cancer of the cervix uteri (Nos. 1, 2 and 3) and the one patient with cancer of the corpus uteri showed an in vitro metabolic activity well within the average values for the whole series. Also, it is noteworthy that the livers of the two patients (Nos. 9 and 12) with definite clinical and pathologic evidence of serious liver disease did not show an impaired in vitro metabolic activity.

\section{DISCUSSION}

The 12 patients studied here represent a heterogeneous group of diseases. Metabolic experiments of the type carried out here could not be done on entirely normal subjects because laparotomy was required to obtain the large liver biopsies which were needed. Since none of the subjects was entirely normal, no absolute conclusion on the normal in vitro metabolic activity of human liver towards estradiol can be deduced from the data reported here. However, there are several factors which suggest that the average amount of estradiol found to be metabolized by human liver in our experiments may not be very different from what normal human liver can metabolize in vitro. These factors are: 1) In this heterogeneous group of patients of different ages and with different types of tumors, the amount of estradiol metabolized was fairly uniform as shown by the sigma value of 11 micrograms for the whole group. 2) Two liver specimens (from Cases 9 and 12), which showed pathologic evidence of advanced liver disease, had a metabolic in vitro activity well within the average range of values for this series. Since all other liver specimens were morphologically normal, it would appear that the metabolic function of liver studied here may be unimpaired even in the presence of structural changes indicative of serious liver damage. 3) One patient in this group (Case 7) did not have cancer and the metabolic activity of her liver was not greater than that of the other patients who had cancer. 4) The amount of estradiol found to be metabolized by this group of patients, although smaller than the average amount metabolized by rat liver in vitro, was of the same general order of magnitude. The rat is considered to be one of the most active species as far as this metabolic function is concerned and our results indicate that human liver differs only to a moderate degree from the rat liver.

On the basis of the results obtained here, one can conclude that an average human liver (weighing 15,000 gms.) is able to metabolize in vitro approximately 11.5 gmus. of $17-\beta$ estradiol per 24 hours at $37^{\circ} \mathrm{C}$. No data are available as yet to indicate in which way this very high level of "in vitro" activity is related to the physiologic activity "in vivo."

Although none of these arguments is decisive, taken together they suggest that our results give a valid indication of the capacity of the human liver to metabolize estradiol in vitro. However, the effect of the pre-operative medication and general anesthesia on this metabolic reaction can not be accurately evaluated. The data also show that this metabolic function was not impaired in three patients with cancer of the cervix and one patient with cancer of the fundus. This fact is interesting in view of the many attempts in recent years to attribute to hyperestrinism an etiological role in cancer of the uterus $(3,4)$. Certain authors have postulated on the basis of indirect evidence that impairment of the estrogenic metabolic function of the liver was associated with the presence of cancer of the cervix and the fundus $(3,4)$. Our data do not support this hypothesis but indicate that advanced disease of the liver as judged from clinical and morphologic observation may not affect its in vitro metabolic activity on estradiol. It seems that this metabolic function should not be impaired in mild liver disease and does not constitute a sensitive test of liver function.

Twombly and Taylor have shown that human liver is able to metabolize estradiol in vitro (5). Our data confirm their conclusion and give information, in addition, on the quantitative aspect of the reaction. However, it is well to remember that the method of study of the metabolic function of the liver used here does not necessarily measure the 
same metabolic alteration which results in inactivation of the estrogens as measured by the bioassay. The possibility has not been ruled out in these experiments that the metabolites from estradiol metabolism by liver are different in patients with cancer of the uterus and other patients or normals. This possibility will be discussed in a future report.

\section{REFERENCES}

1. Lieberman, S., Tagnon, H. J., and Schulman, P., The in vitro metabolism of estrogens by the liver stud- ied by means of a colorimetric method. J. Clin. Invest., 1952, 31, 341.

2. Tagnon, H. J., and Trunnell, J. B., Studies of liver function in patients having cancer of the breast. Cancer, 1948, 1, 472.

3. -Ayer, J. E., and Bauld, W. A. G., Thiamine deficiency and high estrogen findings in uterine cancer and in menorrhagia. Science, 1946, 103, 441.

4. Biskind, M. S., Nutritional therapy of endocrine disturbances. Vitamins \& Hormones, 1946, 4, 147.

5. Twombly, G. H., and Taylor, H. C., Jr., Inactivation and conversion of estrogens in vitro by liver and other tissues from human cancer patients and from mice of strains susceptible to mammary carcinoma. Cancer Research, 1942, 2, 811. 